\title{
Staphylococcus aureus Sepsis in a Patient with Secondary Acute Myelogenous Leukemia
}

\section{Rahmat LT* and Damon LE}

Department of Hematologic Malignancies and Blood and Marrow Transplantation, University of California, USA

*Corresponding author: Rahmat LT, Fellow, Division of Hematology and Blood and Marrow Transplantation, University of California, USA, Ph: 413-329-2289; E-mail: leena.rahmat@ucsf.edu

Received date: May 21, 2018; Accepted date: May 26, 2018; Publish date: June 2, 2018

Copyright: $\odot 2018$ Rahmat LT, et al. This is an open-access article distributed under the terms of the Creative Commons Attribution License, which permits unrestricted use, distribution, and reproduction in any medium, provided the original author and source are credited.

\section{Clinical Image}

We present a case of a 72 year-old female with a history of secondary Acute Myelogenous Leukemia (AML), in the setting of a preceding Myelodysplastic Syndrome (MDS) who developed acute chills, myalgias, and sinus tachycardia following a platelet transfusion given pre-central line placement. As part of the work up for the acute symptoms, a platelet bag residual fluid gram stain was performed and it showed gram positive cocci. Several hours later, the blood smear revealed intracellular bacteria (Figures 1 and 2). Blood cultures grew Staphylococcus aureus approximately eight hours after the platelet transfusion was complete. Intravenous antibiotics were initiated promptly.

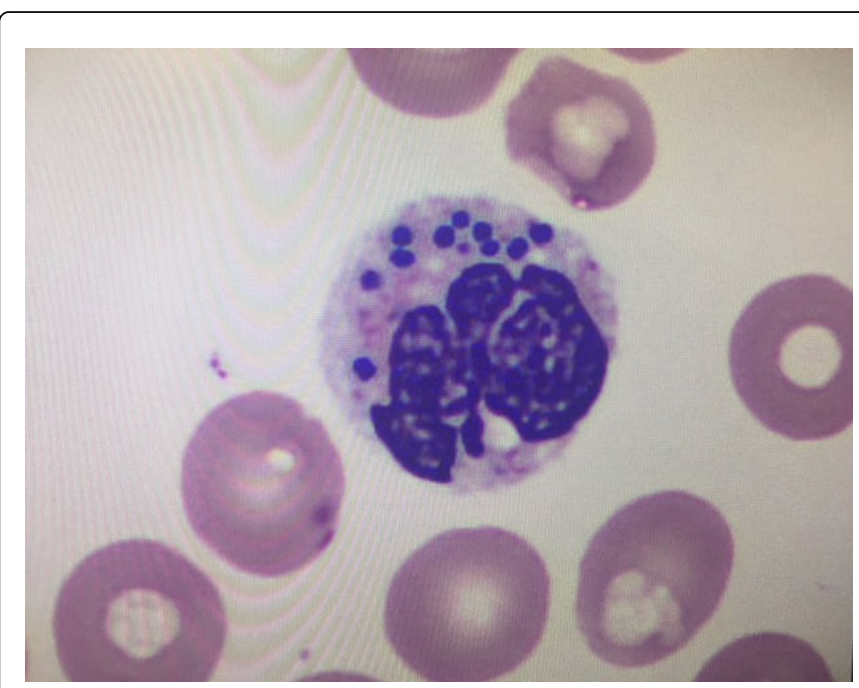

Figure 1: Acute symptoms, a platelet bag residual fluid gram stain was performed and it showed gram positive cocci.

\section{Conflict of Interests}

There are no relevant conflicts of interests.

Figure 2: Several hours later, the blood smear revealed intracellular bacteria.

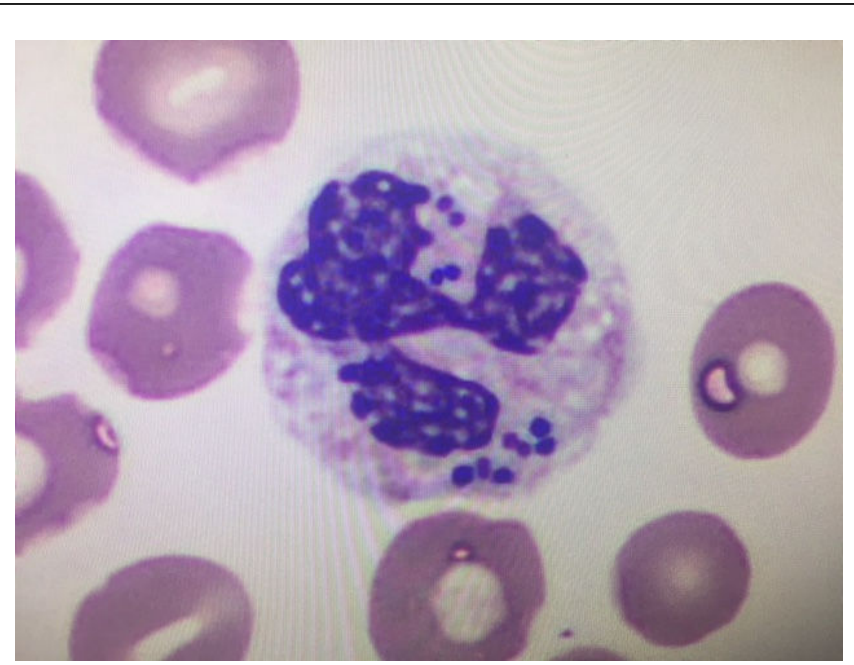

